\title{
KEUNTUNGAN KOMPETITIF ORGANISASI DALAM PERPSEKTIF RESOURCES BASED VIEW (RBV)
}

\author{
Leonardus Ricky Rengkung
}

\begin{abstract}
The uncertaintity and environmental dynamics faced by an organization are highly correlated with the firm's presence in the organization environment. Every organization has to an ability to analyze the organization environment in finding and maintaining its competitive advantage. There are some perspectives explaining about the relationship an organization and its environment, one of them is Resources-Based View $(R B V)$. This Resources-Based View (RBV) is a perspective of strategic management focusing on organization level resources, having organization idiosyncratic resources and maximizing the overall resources of organization compared to competitor. These resources can be a source of relational rents and competitive advantage. The RBV theorizes that the accumulation of resource stocks, that are valuable, rare, imperfectly imitable and non-subsitutable. The resource-based view of the firm provides a useful perspective for explaining firm growth and sustainable competitive advantage. The purpose of this paper is to explain how an organization in finding and maintaining the competitive advantage in the aspect of Resources-based View $(R B V)$
\end{abstract}

Key words : Competitive advantage, Resources-based View, Uncertaintity and dynamism of environment.

\begin{abstract}
ABSTRAK
Ketidakpastian dan dinamika lingkungan yang dihadapi oleh suatu organisasi sangat terkait dengan keberadaan suatu organisasi dalam pada lingkungannya. Organisasi harus memiliki kemampuan untuk menganalisis dinamika lingkungan dengan tujuan mencari, mendapatkan dan mempertahankan kuntungan kompetitifnya. Terdapat beberapa perpektif untuk menjelaskan tentang keterkaitan organisasi dengan lingkungannya, salah satunya adalah Resources Based View (RBV). Perspektif Resources Based View (RBV) merupakan suatu perspektif organisasi dalam bidang stratejik yang mengfokuskan pada tingkat sumberdaya organisasi, berupaya memiliki sumberdaya yang menonjol dan memamksimalkan keseluruhan sumberdaya yang dimiliki organisasi dibandingkan dengan pesaing. Sumberdaya organisasi tersebut akan menjadi sumber keuntungan kompetitif organisasi. Perspective Resources Based View (RBV) menjelaskan tentang sumberdaya yang sifatnya valuable, rare, imitable, and not subsitutable (VRIN) yang mampu menjelaskan pertumbuhan dan keuntungan kompetitif organisasi yang berkelanjutan. Tulisan ini bertujuan untuk menjelaskan cara dan upaya suatu organisasi dalam mencari, mendapatkan dan mempertahankan keuntungan kompetitifnya dalam aspek kepemilikan sumberdaya organisasi dengan perpespektif Resource-based viev (RBV).
\end{abstract}

Kata kunci : Keuntungan kompetitif, Resources-based View, Ketidakpastian dan dinamika lingkungan.

\section{PENDAHULUAN}

\section{Latar Belakang}

Dinamika lingkungan usaha menjadi faktor yang sangat diperhatikan oleh setiap organisasi, baik organisasi publik terlebih organisasi bisnis. Hal ini diakibatkan oleh perubahan-perubahan yang dramatis terjadi dalam lingkungan dimana organisasi tersebut berada yang dapat mempengaruhi eksistensi dari organisasi tersebut. Hal ini sesuai dengan yang dikatakan oleh Jones (1994), bahwa suatu organisasi tidak akan lepas dari pengaruh lingkungan, dan memiliki ketergantungan dalam lingkungan di mana suatu organisasi ini bergerak. 
Lingkungan organisasi itu sendiri merupakan sekumpulan sumberdaya yang terkait, dan tersedia di sekitar di mana organisasi itu berada dan beroperasi, atau secara umum dapat diartikan sebagai sesuatu yang tidak terhingga dan mencakup seluruh elemen yang terdapat diluar organisasi ( $\mathrm{Lu}-$ bis dan Huseini, 2009). Jianwey, et al., (2009) mengutip dari Miles dan Snow (1978), mengemukakan bahwa dalam kondisi lingkungan yang dinamis, organisasi harus memiliki perhatian utama dalam menciptakan strategi untuk bisa mempertahankan dynamic fit antara apa yang organisasi tawarkan dan apa yang lingkungan atur, sehingga organisasi dapat tetap berkembang.

Haberberg dan Rieple (2008) mengemukakan bahwa terdapat dua hal penting terkait dengan lingkungan organisasi, yaitu sebagai suatu sistem yang sangat kompleks serta sulit untuk diprediksi yang dapat mengakibatkan ketidakpastian lingkungan.

Organisasi perlu memahami dinamika lingkungan tersebut sepanjang lingkungan tersebut mempengaruhi aktivitas organisasi, mampu menghadapi ketidakpastian lingkungan ini agar organisasi dapat tetap bertahan dalam lingkungannya. Dampaknya, jika tidak ada upaya strategi menajemen untuk menghadapinya, maka organisasi akan mengalami fase decline dan akhirnya bisnis tersebut akan memasuki fase dissolution yang berujung pada kematian (death) (Jones, 1994)

Dalam kaitannya antara organisasi dan keuntungan kompetitif, maka pertama yang harus diperhatikan tentang proses dan dinamika dari lingkungan organisasi yang terjadi dengan bagaimana upaya yang akan dilakukan organisasi dalam upaya mendapatkan dan mempertahankan suatu keuntungan kompetitif. Hal ini merupakan hal yang penting dalam upaya mendapatkan dasar dan alur pemikiran suatu organisasi untuk mendapatkan keuntungan kompetitifnya. Mempelajari dan menganalisis perilaku lingkungan organisasi akan dapat memahami apa yang akan dilakukan organisasi dalam mencapai keberhasilannya dibandingkan dengan pesaingnya dalam pasar. Pertanyaan yang muncul terkait dengan keuntungan kompetitif suatu organisasi, seperti Apa yang membedakan antara organisasi yang sukses dengan organisasi tidak sukses ? (Ethimios, 2006).
Keuntungan kompetitif merupakan dampak dari kemampuan organisasi untuk memposisikan diri melebihi dalam menciptakan nilai dibandingkan dengan para pesaingnya dan ketidakmampuan pesaing untuk menirunya (Teece, Pisano dan Shuen, 1997). Dengan kata lain, bahwa organisasi harus menciptakan suatu keuntungan kompetisi yang tidak mampu ditiru oleh para pesaing, terlebih dalam menghadapi kondisi bisnis yang semakin mengglobal.

Upaya mempertahankan esksitensinya ketika organisasi menghadapi tantangan, perubahan, ketidakpastian dan dinamika lingkungan sehingga mampu untuk mendapatkan dan mempertahankan keuntungan kompetitifnya memunculkan beberapa paradigma dalam strategic management, seperti paradigma industrial organization view (Porter, 1980), paradigma strategic conflict approach oleh Shapiro (1989), dan paradigma resource-based view (Wernefelt, 1984) yang dikembangkan oleh Rumelt tahun 1984, Barney tahun 1986 dan Dierrickx dan Cool tahun 1989 (Barney dan Clarck, 2007), serta paradigma dynamic capabilities oleh Teece, Pisano dan Sheun (1997).

Semua paradigma tersebut memiliki keunikan yang digunakan organisasi dalam menghadapi ketidakpastian dan dinamika lingkungan suatu organisasi. Paradigma resource-based view (RBV) merupakan salah satu paradigma yang memandang bahwa organisasi memiliki ketergantungan terhadap sumberdaya yang dimiliki ketika berhadapan dengan tingkat persaingan. Borch dan Madsen (2007) mengemukan bahwa konsep resource-based view (RBV) yang dapat merespon pergerakan lingkungan suatu bisnis.

Barney dan Clark (2007) mengatakan bahwa konsep resource-based view dalam disiplin manajemen stratejik pertama kali diperkenalkan oleh Wernefelt (1984) dan oleh Sanches (2007) sebagai "strategically valuable resources", dan melihat bahwa organisasi merupakan bundles of resources. Fuhl (2006) mengutip dari Barney (1995) mengemukakan bahwa looking inside for competitive advantage adalah pusat slogan dari resourcebased view serta pertanyaan berupa why are firms different and how do firms achieve and sustain competitive advantage? Konsep Resource-based viev $(R B V)$ ini membuat ketergantungan suatu or- 
ganisasi untuk mengoptimalkan keseluruhan sumberdaya yang dimiliki dibandingkan dengan para pesaing dalam menghadapi dinamika lingkungan.

Berdasarkan uraian tersebut diatas, maka tulisan ini akan menjelaskan tentang bagaimana cara dan upaya suatu organisasi dalam mendapatkan dan mempertahankan keuntungan kompetitifnya dalam aspek kepemilikan sumberdaya organisasi dengan perpespektif Resource-based viev $(R B V)$.

\section{Tujuan Penulisan}

Penulisan ini bertujuan untuk menjelaskan cara dan upaya suatu organisasi dalam mencari, mendapatkan dan mempertahankan keuntungan kompetitifnya dalam aspek kepemilikan sumberdaya organisasi dengan perpespektif Resourcebased viev $(R B V)$.

\section{TINJAUAN PUSTAKA}

\section{Lingkungan Organisasi}

Lingkungan organisasi merupakan sekumpulan sumberdaya yang terkait dan tersedia dan berada disekitar di mana organisasi itu berada. Jones (1994) mengatakan bahwa lingkungan organisasi merupakan sekumpulan sumberdaya yang mengelilingi suatu organisasi, sedangkan Cunliffe (2008) mendefinisikan sebagai kekuatan umum atau elemen-elemen yang tersedia diluar organisasi, yang dapat mempengaruhi operasional dan keberadaan organisasi.

Jones (2009) mengutip dalam (Sherehly et al., 2007; Tan, 2003), mengatakan, lingkungan organisasi digambarkan sebagai hyper-turbulent, hypercompetitive, dynamic, with discontinuities. Dalam teori organisasi modern, konsep lingkungan organisasi adalah suatu keseluruhan yang berada diluar batas-batas organisasi. Salaman dan Asch (2003) mengatakan bahwa lingkungan usaha merupakan tekanan-tekanan yang datang dari kompetitior. Haberberg dan Rieple (2008), mengemukakan bahwa terdapat empat bentuk lingkungan, yaitu macro-environment, industry lifecycle, industry structure dan nature of competition yang sangat terkait satu dengan lain. Nickels, et al (1996), mengatakan terdapat lima faktor penting dalam lingkungan yang merupakan faktor suksesnya bisnis, yaitu lingkungan ekonomi, lingkungan teknologi, lingkungan kompetitif, lingkungan sosial dan lingkungan bisnis global.

Aaker (1995) membagi lingkungan berupa teknologi, pemerintah, ekonomi, budaya dan demografi, Kast dan Rosenzwig menggambarkannya sebagai segmen budaya, teknologi, pendidikan, politik, legal, sumberdaya natural, demografi, sosial, dan ekonomi.

Jones (1995) mengemukan bahwa sumberdaya-sumberdaya organisasi biasanya terdiri dari bahan mentah, skill pekerja di mana organisasi membutuhkannya untuk melakukan proses produksi; informasi yang dibutuhkan untuk peningkatan teknologi atau keputusan untuk mendapatkan strategi kompetisi; serta dukungan stakeholder berupa konsumen yang membeli barang dan jasa dan lembaga keuangan yang menyediakan modal bagi suatu organisasi.

Terdapat dua hal penting terkait dengan lingkungan organisasi yakni suatu sistem yang sangat kompleks dan sejumlah komponen yang sulit untuk diprediksi dan direspon dan memiliki karakteristik berbeda. Organisasi swasta akan melihat bahwa ketidakpastian lingkungannya sebagai fenomena yang dapat mengganggu aktivitas capaian, sedangkan organisasi publik cenderung melihat lingkungan yang tidak pasti dan dinamis misalnya sebagai fenomena tuntutan perubahan pelayanan publik.

Besarnya lingkungan usaha yang ada dalam organisasi, maka dalam melihat proses dampak bisa mempengaruhi bagi kegiatan organisasi, sering tidak semua elemen lingkungan akan mempengaruhi organisasi, karena itu Lubis dan Huseini (2009) mengatakan bahwa untuk keperluan analisis, lingkungan bisa diartikan sebagai seluruh elemen yang terdapat di luar batas-batas organisasi, yang mempunyai potensi untuk mempengaruhi bagian ataupun organisasi secara keseluruhan.

\section{Faktor-Faktor Penyebab Dinamika Lingkungan Organisasi}

Terdapat tiga faktor yang meningkatkan ketidak pastian lingkungan adalah kompleksitas (complexity), dinamisme (dynamism) dan kekayaan lingkungan (richness of environment) (Jones, 1995) 
atau environmental complexity, environmental stability dan environmental richness (Cunliffe, 2008). Faktor-faktor ini merupakan kesatuan yang tidak bisa dipisahkan dalam lingkungan dan selalu bersifat sangat fleksibel serta saling mempengaruhi satu dengan yang lain.

Kompleksitas (complexity) lingkungan merupakan fungsi daripada kekuatan, jumlah dan ketersediaan sumberdaya-sumberdaya yang ada di lingkungan di mana organisasi harus mengolahnya, dinamisme (dynamism) lingkungan merupakan fungsi daripada cepat lambatnya perubahanperubahan yang terjadi dalam lingkungan yang sifatnya spesifik maupun umum sedangkan kekayaan lingkungan (richness of environment) merupakan seberapa banyak ketersediaan semua sumberdaya yang ada di lingkungan untuk mendukung aktivitas suatu organisasi. Perubahan lingkungan bisnis akan terjadi setiap saat, umumnya berupa gerak perubahan dari salah satu atau gabungan dari faktorfaktor lingkungan luar organisasi. Sebagian dari dampak yang ditimbulkan banyak terbukti telah mempengaruhi datangnya berbagai kesempatan usaha (business opportunities). Jika dikaitkan dengan bentuk dan struktur organisasi, jika organisasi dengan bentuk dan struktur yang baik dengan sistem organisasi yang baik dengan dukungan visi, misi dan rencana aksi business plan yang terencana belum bisa menjamin sukses dalam mencapai tujuannya.

\section{Keuntungan Kompetitif (Competitive Advantage)}

Keuntungan kompetitif suatu organisasi sering diukur dengan capaian kinerja suatu organisasi yang bisa melebihi capaian kinerja oleh pesaingnya. Konsep keuntungan kompetitif merupakan suatu proses yang terjadi dalam manajemen stratejik dan suatu keuntungan kompetitif terjadi jika; (1) organisasi dapat mengembangkan suatu kompetensi dasar yang oleh Prahalad dan Hamel (1990) menyebutnya sebagai core competence; (2) organisasi harus memperhatikan tiga kriteria terkait yaitu mampu menawarkan benefit bagi pelanggan, sulit untuk ditiru, dan memiliki akses terhadap pasar yang berbeda (Erick de Ward, 2008).

Beberapa definisi tentang keuntungan kompetitif, sebagaimana apa yang dikemukakan oleh Barney (1991) dalam Fuhl (2006) adalah suatu or- ganisasi dikatakan memiliki keuntungan kompetitif jika organisasi tersebut sedang mengimplementasikan suatu strategi untuk menciptakan nilai yang secara simultan tidak sedang diimplementasikan oleh para pesaing saat ini dan berpotensi dan juga jika organisasi-organisasi lain tidak mampu untuk meniru keuntungan dari strategi tersebut'.

Tahun 1985, Porter menggunakan istilah sustainable competitive advantage, tanpa mendefinisikan suatu konsep, ketika mempublikasikan suatu ide tentang generic strategies suatu organisasi. Beberapa penulis mendefiniskan keuntungan kompetitif dengan cara mengkuantifikasikan outcome, sebagaimana yang dikemukakan oleh Jones (1995) bahwa suatu organisasi memiliki keuntungan kompetitif jika suatu organisasi memiliki tingkat keuntungan diatas rata-rata tingkat keuntungan dalam industri. Mengacu pada definisi yang dikemukakan oleh Barney bahwa konsep keuntungan kompetitif berhubungan dengan value creating strategy.

Terdapat beberapa teori yang berbeda untuk menjelaskan keuntungan kompetitif seperti competitive forces, strategic conflict, dan resource-based view. Proses perkembangan teori untuk menjelaskannya mengakibatkan munculnya cara pandang atau paradigma yang baru dalam manajemen stratejik. Paradigma yang pertama yang dominan pada tahun 1980-an adalah industrial organization view, competitive forces atau industrial economics approach (Porter,1980). Pendekatan ini menekankan pada peranan struktur dan posisi industri di mana keuntungan kompetisi organisasi terletak pada kemampuan organisasi untuk menciptakan posisi pasar yang superior untuk menghadapi kekuatan kompetitif dan dikenal dengan apa yang disebut five forces, sebagai suatu competitive forces yaitu threat of new entrants, the bargaining power of suppliers, the bargaining power of buyers, the threat of substitutes and the rivalry among existing competitors yang membangun struktur industri. Selajutnya Porter menyatakan bahwa suatu organisasi akan mendapat keuntungan kompetitif jika menjalankan apa yang disebut sebagai generic strategies, baik cost leadership, differentiation atau focus strategy.

Coh (2005) menyebut paradigma kedua yaitu strategic conflict approach (Shapiro, 1989) yang memandang keuntungan kompetitif berasal dari 
kemampuan organisasi untuk bertahan terhadap pesaingnya melalui strategic investment, pricing strategies, signaling, and the control of information. Kedua paradigma ini secara tradisional mengfokuskan pada keuntungan yang dihasilkan dari industri dan posisi kompetitif organisasi, serta mengganggap bahwa suatu industri sebagai tempat semua organisasi untuk saling berkompetisi, dan sebagai sumber untuk mendapatkan keuntungan.

Paradigma yang ketiga adalah resourcebased view (Wernefelt, 1984), yang memfokuskan pada capaian keuntungan kompetitif berdasarkan pada kepemilikan sumberdaya organisasi yang spesifik seperti kapabilitas dan pembelajaran organisasional. Perpektif ini menekankan pada aset dan kapabilitas spesifik organisasi dan keberadaan isolating mechanisms seperti penentuan dasar kinerja organisasi. Dibandingkan dengan 'competitive forces model' yang berfokus pada industri dan lingkungan eksternal organisasi, maka resource-based view menekankan pada pentingnya lingkungan internal organisasi. Model resource-based view ini tergantung pada dua poin, yaitu peranan sumberdaya dalam mendefinisikan organisasi terkait kemampuannya dan keuntungan merupakan suatu return terhadap sumberdaya yang dimiliki/dikontrol oleh organisasi.

\section{Resource-based View (RBV)}

Barney dan Clark (2007) mengatakan bahwa konsep resource-based view dalam disiplin manajemen stratejik pertama kali diperkenalkan oleh Wernefelt (1984) dan oleh Sanches (2007) sebagai "strategically valuable resources" yang kemudian dipopulerkan oleh Barney tahun 1986, tahun1991, dan tahun 1997, yang melihat bahwa organisasi merupakan budles of resources. Fuhl (2006) mengutip dari Barney (1995) mengemukakan bahwa looking inside for competitive advantage adalah pusat slogan dari resource-based view serta pertanyaan berupa why are firms different and how do firms achieve and sustain competitive advantage? Konsep ini membuat ketergantungan suatu organisasi untuk mengoptimalkan keseluruhan sumberdaya yang dimiliki dibandingkan dengan para pesaing. Organisasi akan dianggap memiliki keberhasilan dan mampu mempertahankan eksistensi, jika organisasi mampu memiliki sumberdaya yang unik dan melebihi dengan apa yang dimiliki oleh pesaing. Coo dan Bontis (2002) mengutip dari Huizing dan Bouman mengemukakan bahwa superior performance organisasi tergantung pada kemampuan organisasi untuk mengembangkan keunikan sumberdaya dan kapabilitas yang dimilikinya.

Pemikiran ini berkembang dalam manajemen stratejik terkait dengan keuntungan kompetitif bahwa organisasi akan mendapatkan keuntungan kompetitif jika memiliki sekumpulan sumberdaya yang unggul. Sumberdaya yang unggul adalah berupa aset-aset organisasi yang dianggap istimewa/aneh (idiosyncratic), seperti brand, patent yang diidentifikasikan sebagai faktor penentu untuk mendapatkan keuntungan kompetitif. Karakter sumberdaya organisasi yang dimaksud merupakan sumberdaya yang valuable, rare, imitable, and not subsitutable (VRIN) (Barney, 1991). Valuable memiliki arti bahwa sumberdaya tersebut memiliki nilai yang lebih dibandingkan pesaing, rare berarti bahwa sumber daya tersebut sukar diperoleh di pasar dan hanya dimiliki oleh beberapa organisasi, imitable ketika suatu organisasi tidak memiliki sumber daya, akan mengalami kesulitan untuk mengembangkan atau menirunya, sedangkan nonsubsitutable, bahwa sumberdaya tersebut tidak dapat digantikan.

Karena itu, sumberdaya yang ada tersebut harus ditranformasikan oleh organisasi untuk mendapatkan keuntungan kompetitif. Setiap organisasi memiliki kekuatan dan kelemahan potensial dan aktual, dan adalah sangat penting untuk mendefinisikan dan membedakannya satu dengan yang lain, yang mana uraian ini menjadi dasar pembentukan model strategi organisasi yang disebut resource-based view (RBV) (Penrose, 1959 ; Rubin 1973 ; Andrews 1971; dan Learned, et al. 1969 dalam Sanches (2008). Esensi dasar yang ditunjukkan oleh pendekatan resource-based view ini adalah (1) bahwa antar organisasi memiliki heterogenitas dalam hal pengelolaan sumberdaya dan (2) konsekuensi perbedaan dalam pengelolaan sumberdaya tersebut akan menghasilkan perbedaan kinerja organisasi.

Resource-based view merupakan suatu teori yang banyak dibicarakan dalam berbagai perspektif yang berbeda oleh para peneliti dan penulis dan te- 
lah banyak digunakan untuk bidang penelitian yang berbeda (Pedron, 2009) Pedron (2009) mengutip dari Hokisson et al. (1999) mengemukakan bahwa resource-based view pertama kali diperkenalkan oleh Wernefelt (1984) dalam suatu seminal paper yang merupakan the best paper tahun 1994 yang dipublikasikan dalam Strategic Management Journal. Teori ini berdasarkan pada apa yang dilakukan oleh Penrose tahun 1959, yang menghubungkan antara sumberdaya, kapabilitas dan keuntungan kompetitif dan hal ini merupakan bagian dari teori manajemen stratejik. Pendekatan resource-based view sebagai salah satu bentuk strategi organisasi, menganggap bahwa organisasi merupakan suatu kumpulan aset, sumberdaya dan kompetensi yang bersifat tangible dan intagible yang sulit untuk ditiru oleh pesaing dalam pasar.

Asumsi mengatakan bahwa organisasi sekurang-kurangnya, dalam jangka pendek adalah tergantung pada sumberdayanya pada saat tersebut yang membuat resource-based view menjadi model yang statis. Dengan pandangan resource-based view, Grant (2001) dalam Raduan, et. al (2009) melihat sumberdaya dan kapabilitas memiliki empat karakteristik dalam hubungannnya dengan keuntungan kompetitif yaitu durability, transparency, tranferability, dan replicability. Sumberdaya dilihat sebagai sumber kapabilitas, kapabilitas sebagai sumber keuntungan kompetitif. Hal ini memberikan makna bahwa sumberdaya yang dimiliki organisasi harus memiliki kekuatan dan daya tahan dalam menghadapi persaingan, berkelanjutan, disalurkan dan diserap dalam organisasi serta dapat diolah.

Dalam manajemen stratejik, resource-based view sangat berhubungan dengan sumberdaya dan kapabilitas yang memungkinkan organisasi mendapatkan dan mempertahankan keuntungan kompetitif yang berkelanjutan dan hal ini merupakan asumsi dasar dari resource-based view. Unsur utama dalam resource-based view (RBV) menurut Rowlands G., M dan Kastel, (2004) dalam Pesic (2007), adalah organisasi merupakan sekumpulan sumberdaya dan kapabilitas, serta efektifitas organisasi tergantung pada keseimbangan antara sumberdaya dan kapabilitas pada satu sisi dan sisi yang lain tergantung pada permintaan pelanggan, pertumbuhan organisasi dibatasi oleh sumberdaya dan kapabilitas, keuntungan kompetitif didasarkan pada kapabilitas yang irreproducible dan reproducible. Hal senada dikemukakan oleh Wernerfelt (1984) dalam Helfat dan Lieberman (2002) bahwa resource-based view didasarkan pada dua ide yang utama adalah sumberdaya dan kapabilitas yang berbeda (heteregeneous) yang dimiliki diantara organisasi-organisasi yang berkompetisi dan sumberdaya yang dimiliki organisasi bersifat immobile dengan tujuan untuk mendapatkan dan mempertahankan keuntungan kompetisinya di tengah semakin ketatnya persaingan.

Penekanan peranan sumberdaya dan kapabilitas sebagai sumber dasar dalam strategi organisasi untuk mendapatkan keuntungan telah menjadi fokus penting pada tahun 1990-an dan telah banyak didiskusikan dalam literatur manajemen stratejik. Penekanan peranan sumberdaya dan kapabilitas organisasi sebagai dasar strategi ini, dikarenakan oleh faktor-faktor seperti lingkungan industri organisasi yang semakin tidak stabil dan tidak pasti yang dialami organisasi. Grant (2001) mengemukakan bahwa peranan sumberdaya dan kapabilitas yang dimiliki organisasi merupakan dasar strategi bagi organisasi. Fokus terhadap pemanfaatan, pengelolaan sumberdaya dan penyebaran kapabilitas internal organisasi, dimaksudkan agar organisasi bisa menghadapi ketidakpastian dan dinamika lingkungannya sehingga suatu organisasi dapat bertahan dan mampu mewujudkan tercapai tujuan. Proses ini harus tetap dilakukan oleh organisasi agar dapat bertahan dalam tingkat persaingan yang semakin kompetitif. Banyak organisasi yang tidak mampu bertahan, diakibatkan oleh ketidakmampuan organisasi tersebut dalam mengelola sumberdaya dan kapabilitas yang dimilikinya.

Terdapat sejumlah definisi yang bisa ditemui tentang sumberdaya (resources) dan kapabilitas (capabilities). Setiap definisi mengandung makna keterkaitan satu dengan yang lain antara sumberdaya dan kapabilitas yang dimiliki dalam proses organisasi menuju pada tujuan yang diinginkan. Sumberdaya merupakan semua kekayaan yang dimiliki oleh organisasi sedangkan kapabilitas mengacu pada kemampuan organisasi untuk mengelola sumberdaya dan menjadi hal yang sangat penting dalam suatu organisasi. Amit dan Schoemaker (1993) dalam Helfat dan Lieberman (2002) 
mengatakan sumberdaya adalah kekayaan (asset) produktif yang dimiliki organisasi (the productive assets owned by the firms) sedangkan kapabilitas merupakan kapasitas organisasi untuk menyebarkan sumberdaya dalam mencapai hasil dan tujuan yang ingin dicapai.

Sumberdaya dianggap sebagai sumber dari kapabilitas organisasi sedangkan kapabilitas merupakan sumber utama dari keuntungan. Selanjutnya dikatakan bahwa kapabilitas dapat didefinisikan sebagai kapasitas organisasi untuk mengkombinasikan, assemble, dan menyebarkan (deploy) semua sumberdaya dengan menggunakan pre-determined activities, routines, process, systems dan skill dari para individu, ketika organisasi berupaya untuk memproduksi barang dan jasa bagi pelanggan yang merupakan sumber keuntungan potensial organisasi. Spanos dan Lioukas (2001) dalam Heene, et, all (2008), mengatakan bahwa kapabilitas merupakan suatu proses a firm's day-to-day managerial, technical, and marketing capabilities.

Heene, et al. (2008) mengutip dalam (Barney, 1991; Conner, 1991; Constantin and Lusch, 1994) mengemukakan bahwa sumberdaya internal termasuk didalamnya adalah aset-aset tangible, kapabilitas internal yang spesifik, rutinitas dan pengetahuan yang dikelola oleh organisasi dan organisasi dapat menggunakan sumberdaya tersebut untuk melaksanakan dan menjalankan maksud strateginya. Pedron (2009) mengutip dalam Teece et al (1997) mendefinisikan sumberdaya sebagai firmspecific assets that are difficult if not impossible to imitate, sedangkan capabilities (kapabilitas) adalah apa organisasi dapat lakukan (what a firm can do).

Sanches dan Heene (2004) mengatakan bahwa sumberdaya termasuk segala sesuatu yang tangible dan intagible yang bernilai dan tersedia dalam organisasi yang bisa menciptakan nilai, sedangkan kapabilitas merupakan pola aktivitas yang berulang dalam menggunakan aset (repeatable patterns of action in the use of assets). Barney (1991) membagi sumberdaya dan kapabilitas dalam tiga kategori, yaitu fisik (physical), manusia (human) dan organizational yang termasuk didalamnya adalah aset, kapabilitas, proses organisasional, atribut organisasi, informasi, pengetahuan yang dikontrol oleh organisasi untuk menciptakan strategi dengan tujuan pencapaian efektifitas dan efisiensi. Helfat dan Lieberman (2002) membagi sumberdaya dan kapabilitas menjadi dua dimensi yaitu core vs complementary dan specialized vs generalized. Organisasi membutuhkan sejumlah sumberdaya dalam proses pencapaian tujuannya serta harus memiliki kapabilitas untuk memutuskan jenis sumberdaya apa yang akan digunakan dalam penciptaan nilai. Hal ini merupakan bagian dari strategi organisasi untuk mendapatkan dan mempertahakan daya saing dalam kondisi lingkungan yang semakin kompleks dan tidak pasti.

Setiap organisasi berupaya untuk mendapat sumberdaya terutama berasal dari lingkungannya, karena kepemilikan sumberdaya dapat dianggap sebagai aset dalam menjalankan organisasi. Berbagai upaya bisa dilakukan organisasi untuk mendapat sumberdaya dan akan melalui suatu proses. Proses pembelajaran (learning) merupakan suatu proses yang utama harus dimiliki organisasi, karena organisasi akan selalu berupaya untuk berubah sejalan dengan perubahan yang terjadi pada lingkungan. Proses pembelajaran (learning) akan memberikan kemampuan pada organisasi untuk mendapat sumberdayanya. Sumberdaya ini muncul sebagai akibat adanya organizational learning dan organisasi harus memiliki kemampuan untuk mengelolanya. Pengolahan sumberdaya yang baik akan menghasilkan suatu kompetensi yang tinggi bagi organisasi dan memungkinkan organisasi dapat menghasilkan produk dengan kualitas barang dan jasa yang tinggi dengan harga yang rendah jika dibandingkan dengan pesaing (Winter 1982).

Organisasi harus mengelola sumberdaya yang dimilikinya dengan mengoptimalkan kapabilitas yang dimilikinya dengan mempertimbangkan bahwa sumberdaya yang dimiliki memiliki sifat VRIN (valuable, rare, imitable dan nonsubstituable) dan oleh Barney (1991). VRIN dikatakan sebagai karakteristik sumberdaya unik yang bisa menghasilkan keuntungan kompetitif. Studi yang dilakukan oleh Peteraf (1993) yang dikutip oleh Parida (2008), sumberdaya dikaitkan dengan keuntungan kompetitif berdasarkan pada empat kondisi yaitu : resource heterogeneity, expost limit to competition, imperfect resource mobility, and ex-ante limit to competition. 
KEUNTUNGAN KOMPETITIF DAN RESOURCES BASED VIEW (RBV)

Setiap organisasi selalu berupaya untuk meningkatkan kinerjanya dengan tujuan agar dapat bertahan dalam lingkungan dimana organisasi tersebut bergerak. Mendapatkan dan mempertahankan keuntungan kompetitif, merupakan salah satu tujuan dari suatu organisasi. Keuntungan kompetitif suatu organisasi sering diukur dengan capaian kinerja yang bisa diharapkan melebihi capaian kinerja oleh pesaingnya. Kepemilikan sumberdaya yang kuat dan inovatif merupakan salah satu syarat mutlak yang harus dimiliki organisasi untuk mendapatkan keuntungan kompetitif.

Sumberdaya dalam organisasi diartikan sebagai bagian yang penting dalam proses pencapaian tujuan organisasi baik sumberdaya manusia (human resources), maupun sumberdaya non-manusia (nonhuman resources). Sumberdaya manusia (SDM) merupakan salah satu sumberdaya yang terdapat dalam organisasi, meliputi semua orang yang melakukan aktivitas dengan kemampuan dan kekuatan fisik dan intelktual. Setiap organisasi akan berupaya mendapatkan sumberdaya yang kuat dan baik, karena dengan kempemilikan sumberdaya yang handal maka diharapkan organisasi tersebut akan mampu bertahan dalam lingkungan persaingan yang dinamis. Organisasi dengan sumberdaya yang handal pula diharapkan akan mampu mendapatkan dan mempertahankan keuntungan kompetitifnya.

Sumberdaya yang ada dalam organisasi harus ditranformasikan oleh organisasi untuk mendapatkan dan mempertahankan keuntungan kompetitif. Setiap organisasi memiliki kekuatan dan kelemahan yang potensial dan aktual dalam proses pencapaian keuntungan kompetitif berdasarkan kepemilikan sumberdayanya, dan adalah sangat penting untuk mendefinisikan dan membedakannya dengan kepemilikan sumberdaya manusia organisasi yang lain. Pembedaan keunikan dan kepemilikan sumberdaya antar organisasi sangat jelas dan menjadi dasar pembentukan model strategi organisasi yang disebut resource-based view (RBV) (Penrose, 1959 ; Rubin 1973 ; Andrews 1971; dan Learned, et al. 1969 dalam Sanches (2008).

Resource-based view merupakan suatu teori yang banyak dibicarakan dalam berbagai perspektif yang berbeda oleh para peneliti dan penulis dan telah banyak digunakan untuk bidang penelitian yang berbeda (Pedron, 2009), serta telah dikembangkan para peneliti untuk memahami bagaimana organisasi mendapatkan keuntungan kompetitif dengan menghubungkan antara sumberdaya, kapabilitas dan keuntungan kompetitif dan hal ini merupakan bagian dari teori manajemen stratejik. Pendekatan resource-based view sebagai salah satu bentuk strategi organisasi, menganggap bahwa organisasi merupakan suatu kumpulan aset, sumberdaya dan kompetensi yang bersifat tangible dan intagible yang sulit untuk ditiru oleh pesaing dalam pasar.

Asumsi pendekatan teori resource-based view mengatakan bahwa sumberdaya organisasi sebagai sumber kapabilitas dan kapabilitas sebagai sumber keuntungan kompetitif. Hal ini memberikan makna bahwa sumberdaya yang dimiliki perusahaan harus memiliki kekuatan dan daya tahan dalam menghadapi persaingan, berkelanjutan, disalurkan dan diserap dalam organisasi serta dapat diolah. Dalam manajemen stratejik, resource-based view sangat berhubungan dengan sumberdaya dan kapabilitas yang memungkinkan perusahaan mendapatkan dan mempertahankan keuntungan kompetitif yang berkelanjutan dan hal ini merupakan tujuan dari pendekatan resource-based view.

Unsur utama dalam resource-based view (RBV) menurut Rowlands G., M dan Kastel, (2004) dalam Pesic (2007), adalah perusahaan merupakan sekumpulan sumberdaya dan kapabilitas, serta efektifitas perusahaan tergantung pada keseimbangan antara sumberdaya dan kapabilitas pada satu sisi dan sisi yang lain tergantung pada permintaan pelanggan, pertumbuhan perusahaan dibatasi oleh sumberdaya dan kapabilitas, keuntungan kompetitif didasarkan pada kapabilitas yang irreproducible dan reproducible. Hal senada dikemukakan oleh Wernerfelt (1984) dalam Helfat dan Lieberman (2002) bahwa resource-based view didasarkan pada dua ide yang utama adalah sumberdaya dan kapabilitas yang berbeda (heteregeneous) yang dimiliki diantara perusahaan-perusahaan yang berkompetisi dan sumberdaya yang dimiliki perusahaan bersifat immobile dengan tujuan untuk mendapatkan dan mempertahankan keuntungan kompetisinya di tengah semakin ketatnya persaingan. 
Penekanan peranan sumberdaya dan kapabilitas sebagai sumber dasar dalam strategi organisasi untuk mendapatkan keuntungan telah menjadi fokus penting pada tahun 1990-an dan telah banyak didiskusikan dalam literatur manajemen stratejik. Penekanan peranan sumberdaya dan kapabilitas organisasi sebagai dasar strategi ini, dikarenakan oleh faktor-faktor seperti lingkungan industri perusahaan yang semakin tidak stabil dan tidak pasti yang dialami organisasi. Grant (2001) mengemukakan bahwa peranan sumberdaya dan kapabilitas yang dimiliki perusahaan merupakan dasar strategi bagi perusahaan. Fokus terhadap pemanfaatan, pengelolaan sumberdaya dan penyebaran kapabilitas internal organisasi, dimaksudkan agar organisasi bisa menghadapi ketidakpastian dan dinamika lingkungannya sehingga suatu organisasi dapat bertahan dan mampu mewujudkan tercapai tujuan. Proses ini harus tetap dilakukan oleh organisasi agar dapat bertahan dalam tingkat persaingan yang semakin kompetitif. Banyak organisasi yang tidak mampu bertahan, diakibatkan oleh ketidakmampuan organisasi tersebut dalam mengelola sumberdaya dan kapabilitas yang dimilikinya.

Raduan, et al., (2009) mengutip dari Barney (1991) mengemukakan bahwa suatu organisasi dikatakan memiliki keuntungan kompetitif jika organisasi tersebut sedang menerapkan strategi penciptaan nilai yang tidak secara simultan sedang diimplementasikan oleh para pesaing potensial dan ketika para pesaing tidak mampu untuk meniru keuntungan strategi yang dimilikinya dan dikatakan bahwa organisasi yang berpotensi dan menghasilkan keuntungan kompetitif, maka sumberdaya yang dimiliki organisasi harus memiliki sifat sebagai berikut: it must be Valuable, Rare, Imperfectly imitable, dan Non-substitutable (VRIN).(Barney, 1991). Valuable memiliki arti bahwa sumberdaya tersebut memiliki nilai yang lebih dibandingkan pesaing, rare berarti bahwa sumber daya tersebut sukar diperoleh di pasar dan hanya dimiliki oleh beberapa organisasi, imitable ketika suatu organisasi tidak memiliki sumber daya, akan mengalami kesulitan untuk mengembangkan atau menirunya, sedangkan non-subsitutable, bahwa sumberdaya tersebut tidak dapat digantikan.

Esensi dasar yang ditunjukkan oleh pendekatan resource-based view ini adalah (1) bahwa antar organisasi memiliki heterogenitas dalam hal pengelolaan sumberdaya dan (2) konsekuensi perbedaan dalam pengelolaan sumberdaya tersebut akan menghasilkan perbedaan kinerja organisasi. Dalam hubungannya dengan kerangka VRIO (Valuable, Rare, Immitable dan Organization), maka pengelolaan sumberdaya bertujuan untuk mendapatkan keuntungan kompetitif, karena sebagai sumberdaya memiliki nilai strategis, sehingga dengan proses pengelolaan sumberdaya akan memungkinkan organisasi untuk meningkatkan efisiensi dan efektifitas. Hal ini bertujuan agar organisasi bisa mendapatkan keuntungan karena sumberdaya yang ada menjadi sumber keuntungan kompetitif berkelanjutan dan memiliki nilai strategis (valuable), sumberdaya menjadi faktor yang sulit ditemukan pesaing dan tidak dapat ditiru ( $\mathrm{ra}$ re), sumberdaya organisasi diharapkan tidak dengan mudah diterapkan oleh organisasi lainnya (immitable), dan akhirnya sumberdaya tersebut harus melekat dalam organisasi yang memungkinkan organisasi mengolahnya menjadi sumberdaya yang bernilai strategi yang akhirnya bisa digunakan sebagai sumber keuntungan kompetitif (organization).

Fuhl (2006) mengutip dari Barney (1995) mengemukakan bahwa looking inside for competitive advantage adalah pusat slogan dari resourcebased view serta pertanyaan berupa why are firms different and how do firms achieve and sustain competitive advantage? Konsep ini membuat ketergantungan suatu organisasi untuk mengoptimalkan keseluruhan sumberdaya yang dimiliki dibandingkan dengan para pesaing. Organisasi akan dianggap memiliki keberhasilan dan mampu mempertahankan eksistensi, jika organisasi mampu memiliki sumberdaya yang unik dan melebihi dengan apa yang dimiliki oleh pesaing. Coo dan Bontis (2002) mengutip dari Huizing dan Bouman mengemukakan bahwa superior performance organisasi tergantung pada kemampuan organisasi untuk mengembangkan keunikan sumberdaya dan kapabilitas yang dimilikinya

\section{PENUTUP}

Proses organisasi dalam mencapai tujuan akan dipengaruhi oleh berbagai faktor ketidakpastian dan dinamika lingkungan, seperti kompleksitas (complexity), dinamisme (dynamism), dan kekayaan 
lingkungan (richness of environment). Lingkungan organisasi tersebut menjadi bagian yang tidak terpisahkan dari proses upaya pencapaian organisasi untuk mendapatkan dan mempertahankan keuntungan kompetitifnya.

Keuntungan kompetitif suatu organisasi sering diukur dengan capaian kinerja suatu organisasi yang bisa melebihi capaian kinerja oleh pesaingnya, mampu mengembangkan suatu kompetensi dasar, mampu menawarkan benefit bagi pelanggan, menciptakan keunikan dibandingkan dengan pesaing, mampu mengimplementasikan strategi yang handal, mampu menciptakan nilai bagi organisasi, memiliki tingkat keuntungan diatas rata-rata.

Sumberdaya manusia merupakan salah satu sumberdaya ada dalam organisasi yang harus ditranformasikan oleh organisasi untuk mendapatkan dan mempertahankan keuntungan kompetitif. Pembedaan keunikan dan kepemilikan sumberdaya antar organisasi sangat jelas dan menjadi dasar pembentukan model strategi organisasi yang disebut resource-based view (RBV) yang merupakan suatu pendekatan strategi organisasi yang menganggap bahwa organisasi merupakan suatu kumpulan aset, sumberdaya dan kompetensi yang bersifat tangible dan intagible yang sulit untuk ditiru oleh pesaing dalam pasar.dan sebagai sumber keuntungan kompetitif, dan sumberdaya tersebut bersifat $t$ must be Valuable, Rare, Imperfectly imitable, dan Non-substitutable (VRIN). Valuable memiliki arti bahwa sumberdaya tersebut memiliki nilai yang lebih dibandingkan pesaing, rare berarti bahwa sumber daya tersebut sukar diperoleh di pasar dan hanya dimiliki oleh beberapa organisasi, imitable ketika suatu organisasi tidak memiliki sumber daya, akan mengalami kesulitan untuk mengembangkan atau menirunya, sedangkan nonsubsitutable, bahwa sumberdaya tersebut tidak dapat digantikan. Esensi dasar yang ditunjukkan oleh pendekatan resource-based view ini adala antar organisasi memiliki heterogenitas dalam hal pengelolaan sumberdaya dan konsekuensi perbedaan dalam pengelolaan sumberdaya tersebut akan menghasilkan perbedaan kinerja organisasi.

\section{DAFTAR PUSTAKA}

Aaker, David A. Developing Business Strategies, Fourth Edition (John Wiley \& Sons, Inc, 1995.

Constance E. Helfat and Marvin Lieberman. The Birth of Capabilities : Market Entry and The Importance of Pre-History. A Presentation at DRIUD Nelson and Winter conference, April 2002.

Constance E. Helfat, Dynamic Capabilities Understanding Strategic Change in Organization. Australia : Blackwell Publishing Ltd, Victoria, 2007.

Coo, Chun Wei and Nick Bontis, The Strategic Management of Intellecual Capital and Organizational Knowledge. New York : Oxford University Press, Inc, 2002

Cunliffe, Ann L. Organization Theory. Sage Publication Ltd 1 Olivers Yard 55 City Road London ECIY 1 SP, 2008.

Eisenhardt, Kathleen M. dan Jeffrey A. Martin, Dynamic Capabilities: What Are They? Department of Management Science and Engineering, Stanford University, Stanford, California, U.S.A.Strategic Management Journal Strat. Mgmt. J., 21: 1105-1121 (2000) Copyright Ó 2000 John Wiley \& Sons, Ltd.

Erik de Waard. Engaging Environmental Turbulence, Organizational Determinants for Repetitive Quick and Adequate Responses. Rotterdam : Erasmus Research Institute of Management (ERIM), Rotterdam School of Management (RSM), Erasmus University Rotterdam, 2010, Ref. Number ERIM : EPS-2010-189-STR， ISBN 978-90-5892229-8.

Fuhl, Florian. The Influence Factors of Dynamic Capabilities: The Case of Innovation Speed at Korean Electronics Companies. Dissertation : Graduate School of Business Administration, Economics, Law and Social Sciences (HSG), Dissertation of Doctor of Business Administration of the University of St.Gallen, Druckerei Lauterberg, Ketzin, 2006. 
Grant, Robert M.. The Resource-Based Theory of Competitive Advantage : Implications for Strategy Formulation. California Management Review, 2001.

Haberberg, Adrian and Alison Rieple, Strategic Management Theory and Application. New York : Oxford University Press Inc, 2008.

Hatch, Mary Jo. Organizational Theory, Modern Symbolic and Postmodern Perspective. Oxford University Press, 1997.

Jianwen, Jon Liao, et al. Organizational Dynamic Capability and Innovation : An Empirical Examnination of Internet Firms. Journal of Small Business Management, 47/(3), 2009.

Jones, Gareth R. Organizational Theory Text and Cases. Addison-Wesley Publishing Company Inc, 1995.

Laurence, Paul R. and Jay W. Lorch, Organization and Environment, Managing Differentiation and Integration. Harvard University, Divison of Research Graduate School of Business Administration, Boston, 1967.

Lubis S. B. Hari dan Martani Huseini. Pengantar Teori Organisasi Suatu Pendekatan Makro. Jakarta : Departemen Ilmu Administrasi Fakultas Ilmu Sosial dan Ilmu Politik Universitas Indonesia, ISBN 978-602-95943-00, 2009.

Pedron, Cristiane Drebes. Using The Dynamic Capabilities Perspective to Analyze CRM Adoption : A Multiple Case in Portuguese Organizations. Lisbon : Desertation, Universidade De Technica De Lisboa, Instituto Superior De Economia E Gestao, June 2009.

Pavlou, Paul A. and Omar A. El Sawy, Understanding the "Black Box" of Dynamic capabilities. Under a $3^{\text {rd }}$ round of review in Management Science, March 2005.

Poulis, Ethimios and Paul R. Jackson. Dynamic Capabilities in Complex Environment : A Qualitative Approach. Oslo : European Academy of Management Conference, Doctoral Collogium May 2006, Oslo Norway, 16 May, 2006.
Prahalad, C.K. dan Gary Hamel. The Core Competence of The Coorporation, Harvard Business Review, Copyright 1990 the Presdent and Fellows of Harvard College.

Raduan, C. R., et al. Management, Strategic Management Theories and the Lingkage with Organizational Competitive Advantage from the Resource-Based View. European Journal of Social Science-Volume 11.Number 3, 402-417, 2009.

Sanches, Ron and Anne Heene. The New Strategic Management, Organization, Competition, and Competence. John Wiley \& Sons, Inc, 2004.

Sanches, Ron. A Scientific Critique of the Resource-Base View (RBV) in Strategy Theory, with Competence-Base Remedies for the RBV's Conceptual Deficiencies and Logic Problems. Research in Competence-Based Management, Volume 4, 25 June 2008.

Teece, David J. Explicating Dynamic Capabilities : The Nature and Microfoundations of (Sustainable) Enterprose Performance. Strategic Management Journal Published On Line in Wiley Inter Science DOI:10.1002/smj.640, 20 June 2007. Dynamic Capabilities \& Strategic Management Organizing for Innovation and Growth. New York : Oxford University Press, 2009.

Teece, Gary Pisano, Amy Shuen, Dynamic Capabilities and Strategic Management. Strategic Management Journal, Vol 18:7, 509533, John Wiley \& Sons, Ltd, 1997. Dynamic Capabilities and Their Microfoundations : Implications for Strategic Management. California : Institute for Business Innovation, Haas School of Business, University of California, Barkeley, 2009.

Winter, Sidney G. Understanding Dynamic Capabilities. WP 2002-05, A Working Paper of the Reginald H. Jones Center The Wharton School, University of Pennsylvania, 2002.

Wren A, A. The Evolution of Management Thought.Fourth Edition. John Wiley \& Sons, Inc, 1994. 
Zollo, Maurizio and Sidney Winter. Deliberate Learning And The Evolution of Dynamic Capabilities. 1047-7039/02/1303/0339 1526-5455 electronic ISSN Organization Science, 2002 Informs Vol. 13, No. 3, May-June 2002, pp. 339-351, 2002. 